\title{
Effect of Fermented Winery By-Product Supplemented Rations on the Temperament and Meat Quality of Angus-Hereford X Steers During Feeding in a British Columbia Feedlot
}

\author{
Paul E. Moote ${ }^{1}$, John S. Church ${ }^{2}$, Karen S. Schwartzkopf-Genswein ${ }^{3} \&$ Jonathan D. Van Hamme ${ }^{1}$ \\ ${ }^{1}$ Department of Biological Sciences, Thompson Rivers University, Kamloops, British Columbia, Canada \\ ${ }^{2}$ Department of Natural Resource Science, Thompson Rivers University, Kamloops, British Columbia, V2C 0C8, \\ Canada \\ ${ }^{3}$ Agriculture and Agri-Food Canada, Lethbridge Research Centre, Lethbridge, Alberta, T1J 4B1, Canada \\ Correspondence: John S. Church, Department of Natural Resource Science, Thompson Rivers University, \\ Kamloops, British Columbia, V2C 0C8, Canada. Tel: 1-250-828-5150. E-mail: jchurch@tru.ca
}

Received: July 16, 2014 Accepted: August 18, 2014 Online Published: August 21, 2014

doi:10.5539/jfr.v3n6p124 URL: http://dx.doi.org/10.5539/jfr.v3n6p124

\begin{abstract}
Novel value-added beef products provide improved product differentiation within the beef marketplace. This study evaluated the impacts of supplementing feeds with fermented winery by-products (WB) to produce the novel beef product labeled by industry as "wine-finished beef". To evaluate the impact of this feed, a total of 69 Angus-Hereford X steers were placed in four pens $(n=18,17,17,17)$, one replicate pen per treatment, and fed finishing rations containing equal amounts of either 6-7\% WB or 6-7\% water (Control; C) over a 143 day feeding period. Dietary treatments were not significantly different with respect to energy or chemical contents $(P>0.05)$. Interestingly, the average daily gains $\left(\mathrm{ADG} ; \mathrm{kg}^{*} \mathrm{~d}^{-1}\right)$ of cattle did not differ between diets $(P>0.05)$; however, the ADG of all beef cattle changed over the feeding period $(P<0.0041)$. Cattle temperament, evaluated by measuring their flight speed, changed over time $(P=0.0097)$, but not between diets $(P=0.6938)$. Meat quality attributes including chemical, colour, and tenderness properties did not differ $(P>0.05)$ between diets with the exception of ground steak, which was darker $(P=0.0477)$ in cattle fed WB compared to C supplemented feeds, respectively. Supplementing cattle feeds with WB provides a new marketing stream for beef products with no observed differences to cattle behaviour, animal gains or meat tenderness.
\end{abstract}

Keywords: colour, tenderness, wine, steak, temperament

\section{Introduction}

Feeding animals novel diets, particularly ones that provide potential benefits to both the animal and consumer, is one way to create product differentiation in the meat marketplace. Additionally, consumer trends surrounding beef purchases are influenced by factors including animal production practices (i.e. feeding management), as well as welfare information provided with the product (Napolitano et al., 2010). Co-marketing the production of novel beef products with sustainability and animal welfare attributes could help to facilitate positive consumer responses to a meat product. One such beef product has recently emerged, known as "wine-finished beef" by producers, and is currently marketed in the wine country of the Okanagan Valley of British Columbia, Canada, by feeding feedlot cattle finishing rations containing winery by-products (Findlay, 2010).

Due to escalating feed grain costs experienced in the feedlot industry, there exists a need to reduce dependency on grain-based rations (Hersom et al., 2010; Molina-Alcaide et al., 2008). At the same time, costs associated with the disposal of by-products of the wine-making industry are also increasing as current environmental initiatives require more stringent technologies for disposal, such as solid state fermentation or composting (Arvanitoyannis et al., 2006b). Therefore, the use of winery by-products (WB) as an alternative feed and energy source in feedlot diets could provide an economic benefit to both industries (Arvanitoyannis, et al., 2006a). The major by-products from wine production include grape stalks, pomace, seeds and stems, as well as wine lees, representing 2.5-7.5\%, 15\%, $3-6 \%$ and 3.5-8.5\% of the original grape mass, respectively (Nerantzis and Tartaridis, 2006). Many of these wastes have pharmacological value and can be sold to the pharmaceutical industry as a source of phenol, flavenol, and lignocellulosic compounds (Arvanitoyannis et al., 2006a,b). Winery by-products have been used as dietary 
supplements and feed stuffs, as well as for the production of laccases and phytochemicals (Arvanitoyannis et al., 2006a). Of these products, grape pomace has been used most widely in animal agriculture, including studies with dairy and feedlot cattle, sheep, and goats (Alipour \& Rouzbehan, 2010; Baumgärtel et al., 2007; Hadjipanayiotou \& Louca, 1976; Molina-Alcaide et al., 2008; Nielsen \& Hansen, 2004).

Although grape pomace has been widely used, grape seed extracts have been shown to provide the best source of energy for high-producing ruminants (Baumgärtel et al., 2007). However, the value of seeds to the pharmacological industry is reducing the availability of this product in pomace and as an extract (Nerantzis and Tartaridis, 2006). In the absence of seeds, WB such as grape pomace have been shown to be limited in energy and not sufficient to support animal growth or milk production as a sole animal feed (Abarghuei et al., 2010; Baumgärtel et al., 2007; Hadjipanayiotou \& Louca, 1976; Spanghero et al., 2009). Grape pomace has been successfully used as a co-product with high energy forages in animal feeds, and has been shown to reduce methane emissions from dairy cattle (Hersom et al., 2010; Molina-Alcaide, Moumen, \& Martín-García 2008; Tsiplakou \& Zervas, 2008). Fermented WB, such as wine lees, are wastes produced during the decanting or raking of wine and have been shown to be a source of protein and tannins suitable as feed supplements for ruminants (Molina-Alcaide et al., 2008). As the feeding of winery by-products, such as wine lees, to animals is a relatively new practice, few studies have assessed their potential as a supplemental feed for beef cattle.

During the marketing of "wine-finished" beef in Canada, un-validated claims that feeding wine lees to beef cattle altered their behaviour, and temperament, were reported in the media (Findlay, 2010). Temperament in cattle has been defined and measured in numerous ways, the most common of which involves an animal's response to handling (Schwartzkopf-Genswein et al., 2012). Past research has indicated that animals that differed in their FS also exhibited differences in their personality traits, which has often resulted in differences in their average daily gain (Muller and von Keyserlingk 2006). It is possible that substituting WB for water in cattle feed could alter animal behaviour due to changes made in the energy and carbohydrate content of the diet, as residual levels of alcohol are unlikely to be sufficiently high to alter cattle behaviour (Gregorini et al., 2006).

Diet has been shown to alter cattle behaviour in previous studies; for instance, Gregorini et al. (2006) found that shifts to the carbohydrate concentration of forage corresponded to changes in biting behaviour, a behaviour attributed to elevated tryptophan levels. The addition of tryptophan to cattle feed has also been shown to increase lying and eating behaviours in dairy cattle (Nakanishi et al., 1998). Tryptophan circulates in the blood at low levels and is later converted to serotonin in the brain (Gregorini et al., 2006). Diet can affect this conversion process as carbohydrates stimulate pancreatic B-cells to secrete insulin, which affects the uptake of sugars and non-tryptophan amino acids into peripheral cells (Nelson, 1995). This in turn results in a relatively high ratio of tryptophan to other amino acids in the blood, which then outcompetes other amino acids for access to the central nervous system, selectively crossing the blood brain barrier and producing higher levels of serotonin. Beef cattle diets supplemented with electrolytes or glycerol have also been shown to reduce stress and agitation during transport, likely through this mechanism (Parker et al., 2007; Schaefer et al., 1997). If the inclusion of WB into cattle feeds results in substantial differences in dietary constituents, it may affect cattle behaviour as indicated by FS, and lead to increased gains in the animals as well as yielding more tender meat products (Voisinet et al., 1997).

It is well established that the addition of tryptophan to pig rations results in calmer behaviour as well as lower plasma cortisol concentrations (Guzik et al., 2006; Koopmans et al., 2006; Li et al. 2006; Peeters et al., 2004). Further, meat quality in tryptophan fed pigs was improved compared to control fed pigs with respect to meat colours and 45-minute $\mathrm{pH}$ (Guzik et al., 2006). In various interviews, marketers of "wine-finished" beef claimed that the practice of feeding WB has altered the colour of the final beef product (Findlay, 2010). If supplementing finishing rations with WB can alter cattle behaviour as indicated by FS, it is reasonable to suggest that it might also cause a colour change in the final beef product as well (Voisinet et al., 1997).

The objectives of this study were to: 1 . establish if substantial nutritional differences in rations supplemented with winery by-products exist; 2 . determine the effects of feeding custom feedlot finishing rations supplemented with winery by-products on feed intake, performance, and meat quality in beef cattle; and, 3 . to determine the potential impact of this novel feed ingredient on the behaviour of beef cattle, at the request of the producers and marketers of this new niche beef product. 


\section{Materials and Methods}

\subsection{Experimental Design}

\subsubsection{Animals}

Before commencing this project, animal use research protocols were approved by the Thompson Rivers University animal care committee. The study followed the Canadian Council of Animal Care guidelines for Farm Animals (Canadian Council on Animal Care 2009) and the Canadian Beef Cattle Code of Practice guidelines (Agriculture Canada 1991). Upon commencing the research project, a total of 69 Angus-Hereford X steers $(351.3 \pm 27.9 \mathrm{~kg})$ were purchased from the Stirrup Ranch near Kirsley, BC, Canada and transported $678 \mathrm{~km}$ to a small custom feedlot near Oliver, BC, Canada (Southern Plus Feedlots). Once at the feedlot, cattle were acclimated to finishing rations by stepping up the grain ration content from $0-50 \%$ (20\% oats, $30 \%$ barley) in the diets over a 30 day (d) period. Once acclimated, animals were randomly separated into four freshly cleaned pens, two pens per treatment $(\mathrm{n}=18,17,17$, and 17). To accomplish this, animals were randomly separated, in groups of 3-4 animals at a time, on a first come first serve basis with animals going into pens in a constant order to reduce sampling bias.

\subsubsection{Housing}

Treatment pens were $1600 \mathrm{~m}^{2}(40 \mathrm{~m} \times 40 \mathrm{~m})$ and each contained a concrete feed bunk along one side of the pen. For this experiment, pens shared water bowls with an adjacent pen (one bowl per two pens) that contained animals fed the same diets. Pens were cleaned on a monthly basis, or as needed, using front-end loaders, and bedding of either gypsum or wood chips was added after cleaning.

\subsubsection{Dietary Treatments}

Animals were fed finishing diets containing equal amounts of either 6-7\% winery by-products (WB; 18 and 17 animals per pen) or 6-7\% water (C; 17 and 17 animals per pen) for a 143 day (d) period (Table 1). Wine lees were the sole source of the winery by-products for this experiment, except for one batch, which contained improperly fermented wine not fit for resale. For this reason we refer to the wine supplement as WB, as opposed to wine lees. The oats and barley used in the feeds were of high quality, at least 489 and $618 \mathrm{~kg} \mathrm{~m}^{-3}$, respectively, and rolled on site. Further, malt contents were fermented cereal grains provided from local breweries and the liquid supplement contained minerals and protein designated for beef cattle. Variation in the feed contents and $\% \mathrm{WB}$ and $\% \mathrm{C}$ occurred as a result of a dietary change from corn silage to chopped hay when silage supplies diminished two thirds of the way (d105) through the feeding trial.

Table 1. Wet matter composition of experimental diets used during the 143 day feeding program

\begin{tabular}{lllll}
\hline Item & \multicolumn{2}{c}{ \% Diet (d1-d105) } & \multicolumn{2}{c}{ \% Diet (d106-d148) } \\
& WB & C & WB & C \\
\hline Corn silage & 30 & 30 & 0 & 0 \\
Chopped hay & 0 & 0 & 12 & 12 \\
Fermented cereal grains (malt) & 10 & 10 & 31 & 31 \\
Oats & 20 & 20 & 20 & 20 \\
Barley & 30 & 30 & 28 & 28 \\
Protein and mineral feed supplement & 3 & 3 & 3 & 3 \\
Winery by-products & 7 & 0 & 6 & 0 \\
Water & 0 & 7 & 0 & 6 \\
Percent dry matter $(\%) \pm \mathrm{SEM}$ & $64.3 \pm 0.3$ & $58.5 \pm 1.0$ & $63.3 \pm 0.1$ & $84.6 \pm 4.0$ \\
Energy content $\left(\mathrm{kcal} \mathrm{gm}^{-1} \mathrm{DM} \pm \mathrm{SEM}\right)$ & $4.9 \pm 0.2$ & $4.2 \pm 0.1$ & $4.2 \pm 0.4$ & $4.7 \pm 0.3$ \\
\hline
\end{tabular}

Legend: standard error of the mean (SEM); winery by-products (WB); water (Control; C).

Animals were limit fed freshly prepared feeds twice daily, at 0800 and $1500 \mathrm{hr}$, using industrial feeders equipped with scales ( $\pm 4.55 \mathrm{~kg}$ accuracy) that mixed the ingredients via five large rotors. Weighing back the feed daily to determine feed intake was logistically impractical in this custom feedlot setting. During the experiment, limit feeding was accomplished by the feedlot manager who monitored the daily feed weight delivered to each pen 
through slick bunk demand management, which is routinely utilized at the feedlot and is a common way method of feed delivery in industry as it reduces feed spoilage and can improve gains compared to ad libitum feeding strategies (Alberta Agriculture and Rural Development, 2012; Mader \& Davis, 2004). Cattle were fed the diets until harvest and were provided with an over night fasting period before shipment to the abattoir.

\subsection{Data Collection}

\subsubsection{Feed Analysis and Intake}

Winery by-products (WB) and control (Water, C) rations were compared using near infrared spectrophotometry (NIRS) and bomb calorimetry to determine chemical and energy contents, respectively. To evaluate changes between treatment feeds, three samples of total mixed rations were collected at five events during the feeding period (day 1, 36, 63, 98, and 143) for NIRS; a total of nine samples of each diet, representing three sampling events, were used for bomb calorimetry analyses. Ethanol contents in WB products were evaluated by capillary electrophoresis, and although the total alcohol concentration in mixed feeds was not measured, their contributing energy levels should have been observed through bomb calorimetry as seen with studies on grape pomace (Baumgärtel et al., 2007). In order to evaluate the different feeds, samples were processed within $8 \mathrm{~h}$ of collection to determine dry matter (DM) composition by placing the samples in a drying oven at $60^{\circ} \mathrm{C}$ for $48 \mathrm{~h}$. Samples were then ground using a sample mill (FOSS Cyclotec ${ }^{\mathrm{TM}} 1093$, Hillerød, Denmark) and the feeds were analyzed via NIRS using the Total Mixed Rations parameters of the Ruminant Feed Package following the manufacturer's instructions (FOSS InfraXact ${ }^{\mathrm{TM}}$, Hillerød, Denmark); information supporting this NIRS calibration is listed in Table 2 (FOSS). The dietary components selected for evaluation were determined from Canadian Food Inspection Agency (CFIA) guidelines for feed requirements (Government of Canada, 2012). After NIRS analysis, samples were subjected to oxygen bomb calorimetry to determine the $\mathrm{kcal} \mathrm{g}^{-1} \mathrm{DM}$, using a calibrated Parr oxygen bomb calorimeter (Parr model 1108 combustible bomb and calorimeter) as outlined in Galyean and May (1989).

Table 2. Information on sample size and statistical parameters of results used to prepare the calibrations used to determine the $\%$ ash, fat, protein, ADF, NDF and starch of cattle feeds via NIRS

\begin{tabular}{llllll}
\hline Variable & $\#$ & Mean & SEC & RSQ & SECV \\
\hline Ash & 22 & 3.53 & 0.11 & 0.99 & 0.16 \\
Fat & 23 & 4.55 & 0.09 & 0.95 & 0.2 \\
Protein & 291 & 12.77 & 0.39 & 0.99 & 0.47 \\
ADF & 288 & 20.69 & 1.12 & 0.99 & 1.28 \\
NDF & 172 & 36.29 & 2.35 & 0.98 & 2.76 \\
Starch & 22 & 57.63 & 0.88 & 0.99 & 1.14 \\
\hline
\end{tabular}

Legend: samples (\#); standard error of the calibration (SEC); R2 (RSQ); standard error in cross validation (SECV); acid detergent fibre (ADF); neutral detergent fibre (NDF); Near infrared spectroscopy (NIRS).

\subsubsection{Flight Speed}

A field study was designed to attempt to validate the marketing claims made by the proponents of the product by measuring the impacts of feeding winery by-products on beef cattle flight speed (FS), a quantitative behavioural assessment tool which has been widely used as a measure of beef cattle temperament and has been correlated with weight gain in cattle (Muller \& von Keyserlingk, 2006; Petherick et al., 2009; Schwartzkopf-Genswein et al., 2012; Stockman et al., 2012). After animal weights were recorded and cattle ID was determined via Radio-Frequency identification tags (RFID) tags, the flight speed of cattle was evaluated. Modifications to published methods were that the first set of mirrors and reflectors was placed at $150 \mathrm{~cm}$ from the squeeze exit, and the second set was placed at $245 \mathrm{~cm}$ from the previous set, for a total distance of $395 \mathrm{~cm}$. The apparatus used in this research was provided by Alberta Agriculture Food and Rural Development (Lethbridge, AB, Canada) and consisted of four steel posts, two housing infrared sensors, and two housing mirrors. In this way, cattle exiting the squeeze would trip the first beam, starting a timer, and stop the timer upon breaking the second beam, providing the time between sensors from which velocity was calculated. 


\subsubsection{Meat Quality}

Cattle were weighed and transported $573 \mathrm{~km}$ (approximately a six-hour drive from the feedlot) to an abattoir in two groups: the first groups on day $143(\mathrm{n}=10,5$ per treatment) and the second on day $147(\mathrm{n}=10,5$ per treatment). After slaughter, carcasses were aged for $14 \mathrm{~d}$ in a cooler with temperatures between $0-1.1{ }^{\circ} \mathrm{C}$ and a humidity of $68 \%$ as determined by the abattoir manager. The weights of the right side of the carcasses were compared to determine if changes in diet impacted carcass weight. Dressing percentage and carcass yield were not measured. Two rib eye steaks ( $2.5 \mathrm{~cm}$ thick, longissimus dorsi) were obtained between the eleventh and twelfth rib from each carcass; one steak was used for tenderness evaluation, and the other for meat colour and meat chemistry measures. To ensure meat samples were objectively evaluated, steaks were provided to the analyst 'blind' as the ID of meat samples were not provided until after the analyses were performed. Analyzes on the collected rib-eye steaks were performed 6 hours after sampling.

Dietary impacts on the colour of the surface of red steak meat, the surface of trim fat, and the surface of ground steak samples were determined using a colorimeter (Hunter Lab ColorFlex ${ }^{\circledR}$ EZ, Reston, USA). Any debris created during the removal of the steak from its carcass was removed from the surfaces of steaks prior to measurement. Eight readings from each sample were averaged and the results were reported according to the International Commission on Illumination (CIE) profile as lightness $\left(\mathrm{L}^{*}\right)$, redness $\left(\mathrm{a}^{*}\right)$, and yellowness $\left(\mathrm{b}^{*}\right)(\mathrm{CIE}$, 1978). Additional bloom time was not provided, as steaks had been removed from the carcasses at least $6 \mathrm{~h}$ prior and stored in food safe bags, and meat samples were not dried after they were ground.

Protein, fat, moisture, and collagen contents were determined by an NIRS instrument designed for meat samples (FOSS FoodScan ${ }^{\mathrm{TM}}$ Meat analyzer, Hillerød, Denmark). Rib eye steak samples were trimmed of excess fat and then ground in a commercial grinder (Hobart model FP41, Hobart Food Equipment, Toronto, Canada).

Meat tenderness was evaluated by removing the bone of rib eye meat samples and cooking the meats in a heated clamshell cooker until an internal temperature of $71^{\circ} \mathrm{C}$ was reached; samples were flipped at $40^{\circ} \mathrm{C}$ to ensure consistency in cooking (Agriculture and Life Sciences: Texas A\&M University, Undated). All temperature measures were recorded using a meat thermometer (VWR International, Vandor, USA). Once cooled to room temperature, eight $1-\mathrm{cm}$ diameter cores were removed from each steak and a shear force (SF) test was conducted using a Lloyd Instruments Texture Analyzer with a 50-kN load cell (C.S.C. Force Measurement Inc., Agawam, USA). Cores were sheared using a flat $\mathrm{V}$-shaped blade directed towards the core at a speed of $20 \mathrm{~cm}$ minute ${ }^{-1}$. The instrument then recorded the force (kgf) required to shear each core.

\subsection{Data Analyses}

Statistical analyses were performed using JMP Software V8 (SAS, Carey, USA). Repeated measures multivariate analyses of variance (MANOVA) were used to identify the impacts of treatment feeds on FS over time. For statistical analyses, the pen served as the experimental unit over the five sample periods. Data tables consisting of the average pen scores were organized by sorting determinate values (e.g. FS) into one column and then mixed model MANOVAs were carried out to determine changes to the main factors of time and diet between results, as well as the significance of results towards the interactions of time and diet, using the univariate approach (S.A.S. Institute Inc., 2012). The normality of collected data was determined using the Shapiro-Wilk test in JMP, with results greater than 0.05 deemed as coming from normally distributed samples. Of the data collected, all were from normally distributed populations with the exception of the feed intake and feed chemistry (NIR) values. As such, all changes in meat variation were determined using Student's $t$-tests assuming equal variances, and a post hoc power analyses was conducted to validate results. To address the smaller sample size, post hoc power analyses were completed by providing the software program with the standard deviation, sample size, and mean difference between values for each result. These power tests yielded values above $80 \%$ in all cases with the exception of observed changes to ground steak colour and feed intake, which had power values of $45 \%$ and $27 \%$, respectively. These post hoc results indicate that despite the small sample size used in this study, in the majority of cases, there was sufficient statistical power in our tests to detect differences between the two groups at the 0.05 significance level. For all the statistical analyses, significance was declared at $P \leq 0.05$ and trends at $0.05<P<0.10$.

\section{Results}

\subsection{Feed Analysis}

Analysis of treatment feeds showed no differences $(P>0.10)$ between the two diets with respect to percentages of ash, crude fibre, fat, moisture, protein, and total dietary nitrogen for each of the total mixed rations. Further, no changes between the WB-supplemented and control rations were observed in the percent dry matter or energy 
contents of the feeds, which were compared on a dry matter basis $(P=0.4897$ and 0.7516 , respectively; Table 3$)$. The ethanol contents of four separate WB batches were found to be $10.6 \%(n=4)$.

Table 3. NIRS analysis of ash, fat, protein, ADF, NDF, starch, TDN, as well as the amounts of dry matter and calories contained within the WB and C supplemented cattle finishing rations

\begin{tabular}{llllllll}
\hline Diet & Measure & Units & $\mathrm{n}$ & Mean & STDEV & $t$ & $P$ \\
\hline WB & Ash & $\%$ & 15 & 4.10 & 0.33 & -1.1900 & 0.2449 \\
C & & & 13 & 4.69 & 0.36 & & \\
WB & Fat & $\%$ & 15 & 1.03 & 0.33 & -1.3440 & 0.1905 \\
C & & & 13 & 1.65 & 1.75 & & \\
WB & Protein & $\%$ & 15 & 14.07 & 1.00 & -1.1960 & 0.2424 \\
C & & & 13 & 15.55 & 4.70 & & \\
WB & ADF & $\%$ & 15 & 14.17 & 2.03 & -0.6550 & 0.5185 \\
C & & & 13 & 15.24 & 6.00 & & \\
WB & NDF & $\%$ & 15 & 21.61 & 2.34 & -1.4790 & 0.1512 \\
C & & & 13 & 25.18 & 9.04 & & \\
WB & Starch & $\%$ & 15 & 50.51 & 3.21 & 0.7620 & 0.4530 \\
C & & & 13 & 48.86 & 7.66 & & \\
WB & TDN & $\%$ & 15 & 78.94 & 2.10 & 0.2780 & 0.7841 \\
C & & & 13 & 78.63 & 3.48 & & \\
WB & DM & $\%$ & 15 & 64.32 & 3.53 & 0.3200 & 0.7516 \\
C & & & 13 & 65.84 & 18.12 & & \\
WB & Energy & \multirow{2}{*}{$\mathrm{kcal} \mathrm{g}^{-1} \mathrm{DM}$} & 9 & 4.44 & 0.47 & -0.7070 & 0.4896 \\
$\mathrm{C}$ & & & 9 & 4.61 & 0.55 & & \\
\hline
\end{tabular}

Legend: Near infrared spectroscopy (NIRS); acid detergent fibre (ADF); neutral detergent fibre (NDF); total dissolved nutrients (TDN); dry matter (DM); winery by-products (WB); water (Control; C).

\subsection{Growth and Performance of Angus-Hereford Cross Cattle}

The ADG results are presented in Table 4. No significant differences to ADG $(P=0.7229)$ were observed between animals fed either the WB or $\mathrm{C}$ treatment feeds over time. Overall, the ADG of animals decreased over time, with the ADG of animals fed the WB ration decreasing from 1.54 to $1.25 \mathrm{~kg} \mathrm{~d}^{-1}$, while the ADG of animals fed the C ration decreased from 1.69 to $1.10 \mathrm{~kg} \mathrm{~d}^{-1}(P=0.0041)$. The power with which we were able to detect changes in ADG among the four pens was determined to be 0.63 .

\subsection{Animal Mortality}

During the experiment, four cattle were removed from the study by the feedlot staff over bloat concerns, three of which were fed $C$ rations (day 95, 97, 112) and one fed WB rations (day 106). Of these animals, one fatality was observed and catalogued from the animals fed the $\mathrm{C}$ ration. The cause of death was thought to be bloat as determined by the onsite animal health technician.

\subsection{Flight Speed}

Cattle flight speed (FS) was found to decrease over the duration of the experiment $(P=0.0097)$. However, when comparing flight speeds between individuals fed WB and C diets, no statistical differences were observed $(P=$ $0.6938)$, and similarly no statistically significant interactions were observed over time with respect to diet $(P=$ 0.7842; Table 4). The observed power of our experiment to detect changes in flight speed was 0.61 for the four sample pens. 
Table 4. Impacts of a 143-d diet supplemented with winery by-products (WB) or water (C) on the gains, ADG and FS on the temperament and performance of cattle

\begin{tabular}{|c|c|c|c|c|c|c|c|c|c|c|}
\hline \multirow[b]{2}{*}{ Diet } & \multirow[b]{2}{*}{ Measure } & \multirow[b]{2}{*}{ Units } & \multicolumn{5}{|c|}{ Time on feed (d) } & \multirow[t]{2}{*}{$P$ (diet) } & \multirow[t]{2}{*}{$P$ (time) } & \multirow[t]{2}{*}{$P($ time $\times$ diet $)$} \\
\hline & & & 1 & 36 & 64 & 98 & 143 & & & \\
\hline WB & $\mathrm{n}$ & & 35 & 35 & 35 & 35 & 34 & $\mathrm{n} / \mathrm{a}$ & $\mathrm{n} / \mathrm{a}$ & $\mathrm{n} / \mathrm{a}$ \\
\hline $\mathrm{C}$ & & & 33 & 33 & 33 & 31 & 30 & & & \\
\hline WB & Weight & $\mathrm{kg}$ & $351 \pm 2^{\mathrm{E}}$ & $405 \pm 4^{\mathrm{D}}$ & $450 \pm 6^{\mathrm{C}}$ & $496 \pm 0^{\mathrm{B}}$ & $553 \pm 1^{\mathrm{A}}$ & 0.03 & $<0.01$ & 0.12 \\
\hline $\mathrm{C}$ & & & $352 \pm 7^{\mathrm{E}}$ & $411 \pm 5^{\mathrm{D}}$ & $456 \pm 10^{\mathrm{C}}$ & $506 \pm 9^{\mathrm{B}}$ & $556 \pm 8 .^{\mathrm{A}}$ & & & \\
\hline WB & Gains & $\mathrm{kg}$ & & $130 \pm 3^{\mathrm{E}}$ & $230 \pm 8^{\mathrm{D}}$ & $337 \pm 1^{\mathrm{C}}$ & $447 \pm 4^{\mathrm{A}}$ & 0.05 & $<0.01$ & 0.47 \\
\hline $\mathrm{C}$ & & & & $119 \pm 4^{\mathrm{E}}$ & $218 \pm 8^{\mathrm{D}}$ & $319 \pm 5^{\mathrm{B}}$ & $442 \pm 6^{\mathrm{A}}$ & & & \\
\hline WB & $\mathrm{ADG}$ & $\mathrm{kg} \mathrm{d}^{-1}$ & & $1.54 \pm 0.1^{\mathrm{AB}}$ & $1.50 \pm 0.1^{\mathrm{AB}}$ & $1.35 \pm 0.2^{\mathrm{BC}}$ & $1.25 \pm 0.0^{\mathrm{CD}}$ & 0.72 & $<0.01$ & 0.31 \\
\hline $\mathrm{C}$ & & & & $1.69 \pm 0.0^{\mathrm{A}}$ & $1.51 \pm 0.2^{\mathrm{AB}}$ & $1.4 \pm 0.1^{\mathrm{BC}}$ & $1.10 \pm 0.0^{\mathrm{D}}$ & & & \\
\hline WB & FS & $\mathrm{m} \mathrm{s}^{-1}$ & $2.15 \pm 0.2^{\mathrm{A}}$ & $1.82 \pm 0.1^{\mathrm{ABCD}}$ & $1.84 \pm 0.1^{\mathrm{ABC}}$ & $1.67 \pm 0.3^{\mathrm{CD}}$ & $1.45 \pm 0.1^{\mathrm{D}}$ & 0.69 & 0.01 & 0.78 \\
\hline $\mathrm{C}$ & & & $2.05 \pm 0.2^{\mathrm{AB}}$ & $1.81 \pm 0.3^{\mathrm{ABCD}}$ & $1.76 \pm 0.2^{\mathrm{BCD}}$ & $1.56 \pm 0.1^{\mathrm{CD}}$ & $1.61 \pm 0.1^{\mathrm{CD}}$ & & & \\
\hline
\end{tabular}

Legend: average daily gains (ADG); flight speeds (FS) of cattle; ${ }^{\mathrm{A}}$ similar letters within each measurement indicate statistically similar results; standard error of measurements are indicated after each value; winery by-products (WB); water (Control; C).

\subsection{Carcass Characteristics and Meat Quality}

Carcass weights are presented in Table 5 . No statistically significant differences $(P=0.4399)$ were observed in the carcass half weights between treatments, indicating that all carcasses chilled similarly and that any changes to meat properties might be the result of the feed differences, and not simply a result of the energy contents of the finishing rations. Tables 5-7 summarize the results of changes to chemical, tenderness, and colour characteristics of 14-d aged rib eye steaks measured using near infrared spectrophotometric, shear force, and calorimetric tests, respectively. Results presented in Table 6 show that no differences $(P>0.34)$ were observed in the protein, fat, moisture, and collagen contents of WB and C steak samples. Similarly, the tenderness of steaks was not significantly impacted by diet $(P=0.2343)$ (Table 5$)$. When comparing steak meat colour, no statistically significant differences $(P>0.17$; Table 7) were observed between the WB or $\mathrm{C}$ treatments. However, the colour of ground steak samples was lighter $(P=0.0477$; Table 7) in C than WB finished cattle; the incidence of dark, firm, and dry (DFD) meat or $\mathrm{pH}$ of meat samples was not evaluated in this study, but no obvious cases of DFD were detected by personnel at slaughter. Further, trends towards significance were observed in the fat colours between meats from treatment diets. Specifically, the fats of steak meats were found to be more red in samples from cattle fed the $\mathrm{C}$ feeds $(P=0.0517$; Table 7$)$. Other than these two findings, there were no other changes to the colour or tenderness of rib eye steak samples analyzed from WB and C fed cattle. The statistical power with which we were able to detect differences within half carcass weights, as well as steak and trim meat colours, was found to be greater than 0.8825 . However, the observed power within our experiment to discern changes to ground meat colour was found to be 0.4514 , which was a result of reduced sample size to accommodate tenderness evaluations. 
Table 5. Half weights of carcasses and the observed tenderness of resulting steaks determined using the shear force test between WB and C fed cattle fed

\begin{tabular}{llllllll}
\hline Diet & Value & Units & $\mathrm{n}$ & Mean & STDEV & $t$ & $P$ \\
\hline WB & Weights & $\mathrm{kg}$ & 10 & 146.0 & 7.18 & -0.790 & 0.4399 \\
$\mathrm{C}$ & & & 10 & 148.9 & 9.12 & & \\
WB & Tenderness & $\mathrm{kgf}$ & 32 & 2.92 & 0.77 & 1.203 & 0.2343 \\
$\mathrm{C}$ & & & 24 & 2.71 & 0.51 & & \\
\hline
\end{tabular}

Legend: load at maximum (kgf); winery by-products (WB); water (Control; C).

Table 6. NIRS analysis of \% protein, fat, moisture, and collagen contained in steak samples from WB or C fed cattle

\begin{tabular}{lllllll}
\hline Diet & Item & $\mathrm{n}$ & Mean & STDEV & $t$ & $P$ \\
\hline WB & Protein & 5 & 21.93 & 0.91 & -0.325 & 0.7562 \\
C & & 3 & 22.11 & 0.24 & & \\
WB & Fat & 5 & 13.17 & 4.30 & -1.030 & 0.3429 \\
C & & 3 & 16.22 & 3.51 & & \\
WB & Moisture & 5 & 64.90 & 3.24 & 0.864 & 0.4210 \\
C & & 3 & 62.91 & 2.95 & & \\
WB & Collagen & 5 & 1.96 & 0.45 & 0.044 & 0.9667 \\
C & & 3 & 1.95 & 0.43 & & \\
\hline
\end{tabular}

Legend: Near infrared spectroscopy (NIRS); winery by-products (WB); water (Control; C).

\section{Discussion}

\subsection{Feed Analysis}

The addition of winery by-products (WB) into finishing rations was found to not alter the chemical and energy contents of the feed, potentially because they were not previously concentrated or in high enough concentrations. These results are in agreement with previous studies that show grape pomace is an insufficient sole source of energy (Abarghuei et al., 2010; Baumgärtel et al., 2007; Spanghero et al., 2009). Further, as the diets contained less than $7 \% \mathrm{WB}$, and no seeds were present in these products, these results were expected and in agreement with Spanghero et al., (2009) who stated that the uses of de-seeded grape pomace were limited as feeds for high producing ruminants.

\subsection{Growth and Performance of Angus-Hereford Cross Cattle}

Supplementing finishing rations with WB was not found to alter the average daily gains in Angus-Hereford X cattle, likely due to the lack of energy change between diets. These results are also in agreement with previous research on the impacts of feeds supplemented with active yeast cultures, as they also did not alter the growth and performance of cattle fed both corn silage and pasture-based diets (Cabrera et al., 2000; Lesmeister et al., 2004; Mir \& Mir, 1994). The lack of statistically significant changes to the ADG of WB fed cattle suggests that the WB does not hold the potential to alter animal performance, or that the contents of micronutrients contained within WB, such as condensed tannins, alcohol, were at insufficient concentration to statistically impact animal performance.

As the observations of bloat in this study were not large enough to generate statistically relevant results, it is not possible to evaluate the impacts of WB on the occurrence of bloat in cattle. Other studies have shown that feeds containing elevated levels of CT can reduce the occurrence of bloat by suppressing the activity of rumen microbes. Specifically, in vivo studies of lamb micro flora found that the inclusion of tannins into feeds increased the numbers of the bacteria Butyrivibrio fibrisolvens, while decreasing the abundance of Butyrivibrio proteoclasticus (Vasta et al., 2010). Also, CT and active yeast feeds have been found to reduce bloat scores and rumen acidosis, respectively, in cattle (Min et al., 2006; Mir \& Mir, 1994). These results were reported by Min et al. (2006), who found that supplementing the diets of cattle grazing winter wheat with quebracho CT reduced bloat scores as well 
as increased weight gains. Mir and Mir (1994) found that rumen acidosis, caused by grain overload, was reduced in animals fed yeast-supplemented feeds. Finding diets that can reduce bloat in feedlot rations provides an ideal way to reduce the need for bloat preventing antimicrobials, such as monensin.

Table 7. Colorimetric comparisons of rib eye meats (a), trim fats (b), and ground rib eye steaks (c) from 14 day aged meat samples of cattle fed WB or C supplemented feeds

\begin{tabular}{llllllll}
\hline (a) Meat & Diet & Colour & $\mathrm{n}$ & Mean & STDEV & $t$ & $P$ \\
\hline & WB & L*$^{*}$ & 9 & 39.86 & 3.42 & -0.361 & 0.7231 \\
& C & & 8 & 40.34 & 1.51 & & \\
& WB & $\mathrm{a}^{*}$ & 9 & 19.75 & 2.33 & -0.881 & 0.3920 \\
& $\mathrm{C}$ & & 8 & 20.58 & 1.32 & & \\
& WB & $\mathrm{b}^{*}$ & 9 & 17.40 & 1.86 & -0.673 & 0.5109 \\
& $\mathrm{C}$ & & 8 & 17.89 & 0.90 & & \\
(b) Fat & WB & $\mathrm{L}^{*}$ & 10 & 62.70 & 5.72 & 0.487 & 0.6340 \\
& $\mathrm{C}$ & & 6 & 61.46 & 3.20 & & \\
& WB & $\mathrm{a}^{*}$ & 10 & 6.77 & 1.33 & -2.126 & 0.0517 \\
& $\mathrm{C}$ & & 6 & 8.44 & 1.80 & & \\
& WB & $\mathrm{b}^{*}$ & 10 & 16.39 & 1.83 & -1.416 & 0.1786 \\
& $\mathrm{C}$ & & 6 & 17.82 & 2.17 & & \\
(c) Ground & WB & L* & 4 & 49.02 & 2.35 & -2.609 & 0.0477 \\
& $\mathrm{C}$ & & 3 & 54.59 & 3.36 & & \\
& WB & $\mathrm{a}^{*}$ & 4 & 23.14 & 1.20 & 1.405 & 0.2189 \\
& $\mathrm{C}$ & & 3 & 2.58 & 2.58 & & \\
WB & $\mathrm{b}^{*}$ & 4 & 22.04 & 0.22 & -1.158 & 0.2992 \\
& $\mathrm{C}$ & & 3 & 0.94 & 0.94 & &
\end{tabular}

Legend: Lightness $\left(\overline{\left.\mathrm{L}^{*}\right)}\right.$; red colour $\left(\mathrm{a}^{*}\right)$; yellow colour $\left(\mathrm{b}^{*}\right)$; winery by-products $(\mathrm{WB})$; water $($ Control; $\mathrm{C})$.

\subsection{Flight Speed}

This study identified that cattle became habituated to handling over the duration of the study, as indicated by increasingly slower cattle flight speeds as the study progressed. This relationship is supported by other studies that found cattle habituated to handling over time (Petherick et al., 2009; Stockman et al., 2012). Diet was not found to alter cattle behaviour in this study as measured by flight speed. Currently, no research has been conducted on the impacts of WB on ruminant behaviour. Previous research on the role of diet on cattle behaviour has found that providing oral supplements of tryptophan to beef cattle produced sedative effects as well as increased lying and eating behaviours (Nakanishi et al., 1998). Supplementing cattle diets with electrolytes, such as Nutricharge ${ }^{\mathbb{B}}$, has also been found to reduce the stress of transport in animals, improving carcass gains and yield grades during transport (Schaefer et al., 1997). As no statistically relevant changes to the chemical and energy contents of experimental diets were observed, it is somewhat expected that the diets tested would not alter the flight speeds of cattle.

\subsection{Carcass Characteristics and Meat Quality}

Hot carcass weights were not different between WB or C feed fed animals. Furthermore, as carcass weights and caloric contents of feeds did not differ, changes to meat quality were most likely the result of the micronutrients in the treatment diet and not the chilling properties of the individual carcasses. Our results, observing changes to the lightness of ground steak meats ( $\mathrm{L}^{*}$ ) between WB and C treatments, are consistent with other ruminant studies. For example, Luciano et al., (2009) found similar colour patterns when supplementing lamb diets with quebracho tannins, which were potentially caused by increased metmyoglobin formation in animals fed tannin-supplemented feeds. Similar research using by-products of the citrus industry has also been conducted on the impacts of 
supplemented diets on lamb meat; in their paper, Scerra et al., (2001) found citrus pulp supplemented diets can lead to slightly more tender meats potentially created by increasing the moisture content of meats. Additionally, citrus pulp inclusive diets may also reduce the redness of lamb meats, which was observed in the fats of the WB steaks, albeit at non-significant levels when compared to $C$ animals (Caparra et al., 2007). Since statistically significant changes to animal behaviour, measured by the FS of cattle, or chemical properties of treatment feeds were not observed in this study it is expected that the changes to meat colour observed were likely caused by components not measured in this study, such as CT, and not animal behaviour.

\section{Conclusion}

Winery by-products (WB), excluding seeds, have been previously found to not be an effective sole energy source for cattle finishing rations as they do not increase the energy or chemical contents of feeds. However, as supplement to high energy rations, WB may potentially compliment high-energy rations through additions of nutritive factors not yet identified, such as condensed tannins. As a co-product, WB were found to be a safe and economical feed supplement in finishing rations for Angus-Hereford X cattle as they were found to reduce the feed intake of cattle, while not altering their temperament or weights during feeding or at slaughter. Interestingly, ground muscle meats were found to be darker in colour from animals fed this co-product indicating a potential for product differentiation within the marketplace. No statistically significant differences were observed in the FS between cattle fed the different diets, suggesting that the behaviour of cattle is likely unaffected by the inclusion of WB. Further research in this area should be conducted to repeat and validate this work and verify if unidentified nutritive factors exist in the WB-supplemented feed. Understanding the biochemical processes that impacted the colour changes observed in this study is required to ensure consistent production, especially if the overall goal is to improve meat quality.

\section{References}

Abarghuei, M. J., Rouzbehan, Y., \& Alipour, D. (2010). The influence of the grape pomace on the ruminal parameters of sheep. Livestock Science, 132(1-3), 73-79. http://dx.doi.org/10.1016/j.livsci.2010.05.002

Agriculture and Life Sciences: Texas A\&M University. (Undated). Standardized Warner-Bratzler Shear Force Procedures for Genetic Evaluation. Retrieved August 11, 2014, from http://meat.tamu.edu/research/shear-force-standards/

Agriculture Canada. (1991). Recommended Code of Practice for the Care and Handling of Farm Animals: Beef Cattle. Agriculture Canada Publication 1870/E.

Alberta Agriculture and Rural Development. (2012). Nutrition and Management: Principles of Bunk Management. Retrieved June 7, 2013, from http://www1.agric.gov.ab.ca/\$department/deptdocs.nsf/all/beef11704\#Clean

Alipour, D., \& Rouzbehan, Y. (2010). Effects of several levels of extracted tannin from grape pomace on intestinal $\begin{array}{lllll}\text { digestibility of soybean meal. Livestock } & \text { Science, } & \text { 128(1-3), } & \text { 87-91. }\end{array}$ http://dx.doi.org/10.1016/j.livsci.2009.11.003

Arvanitoyannis, I. S., Ladas, D., \& Mavromatis, A. (2006a). Potential uses and applications of treated wine waste: a review. International Journal of Food Science and Technology, 41(5), 475-487. http://dx.doi.org/10.1111/j.1365-2621.2005.01111.x

Arvanitoyannis, I. S., Ladas, D., \& Mavromatis, A. (2006b). Wine waste treatment methodology. International Journal of Food Science \& Technology, 41(10), 1117-1151. http://dx.doi.org/10.1111/j.1365-2621.2005.01112.x

Baumgärtel, T., Kluth, H., Epperlein, K., \& Rodehutscord, M. (2007). A note on digestibility and energy value for sheep of different grape pomace. Small Ruminant Research, 67(2-3), 302-306. http://dx.doi.org/10.1016/j.smallrumres.2005.11.002

Cabrera, E. J. I., Mendoza, M. G. D., Aranda, I. E., Garcia-Bojalil, C., Barcena, G. R., \& Ramos, J. J. A. (2000). Saccharomyces cerevisiae and nitrogenous supplementation in growing steers grazing tropical pastures. Animal Feed Science and Technology, 83(1), 49-55. http://dx.doi.org/10.1016/S0377-8401(99)00109-1

Cafe, L. M., Robinson, D. L., Ferguson, D. M., McIntyre, B. L., Geesink, G. H., \& Greenwood, P. L. (2011). Cattle temperament: persistence of assessments and associations with productivity, efficiency, carcass and meat quality traits. Journal of Animal Science, 89(5), 1452-1465. http://dx.doi.org/10.2527/jas.2010-3304

Canadian Council on Animal Care. (2009). The Care and Use of Farm Animals in Research. CCAC., Ottawa, ON: $12-15$. 
Caparra, P., Foti, F., Scerra, M., Sinatra, M. C., \& Scerra, V. (2007). Solar-dried citrus pulp as an alternative energy source in lamb diets: Effects on growth and carcass and meat quality. Small Ruminant Research, 68(3), 303-311. http://dx.doi.org/10.1016/j.smallrumres.2005.11.015

De L'Eeclairage-CIE, C. I. (1978). Recommendations on uniform color spaces, color difference equations and psychometric color terms. CIE Publication, 15, 9-12.

Curley, K. O., Paschal, J. C., Welsh, T. H., \& Randel, R. D. (2006). Technical Note: Exit velocity as a measure of cattle temperament is repeatable and associated with serum concentration of cortisol in Brahman bulls. Journal of Animal Science, 84(11), 3100-3103. http://dx.doi.org/10.2527/jas.2006-055

Findlay, S. (2010, 05). Meet the red-wine-swilling cows. Macleans.ca. Retrieved September 18, 2012, from, http://www2.macleans.ca/2010/08/05/i-think-youve-had-enough-maisy/

Galyean, M. L., \& May, T. (1989). Chapter IV Energy in Animal Nutrition. In Laboratory Procedure in Animal Nutrition Research, New Mexico states University, USA, 44-49.

Government of Canada, Canadian Food Inspection Agency. (2012). Chapter 2 - Data Requirements for Single Ingredient Approval and Feed Registration. Retrieved March 27, 2013 from http://www.inspection.gc.ca/animals/feeds/regulatory-guidance/rg-1/chapter-2/eng/1329298059609/132929 8179464.

Gregorini, P., Tamminga, S., \& Gunter, S. A. (2006). Review: Behavior and Daily Grazing Patterns of Cattle. The Professional Animal Scientist, 22(3), 201-9.

Guzik, A. C., Matthews, J. O., Kerr, B. J., Bidner, T. D., \& Southern, L. L. (2006). Dietary tryptophan effects on plasma and salivary cortisol and meat quality in pigs. Journal of animal science, 84(8), 2251-2259. http://dx.doi.org/10.2527/jas.2005-292

Hadjipanayiotou, M., \& Louca, A. (1976). A note on the value of dried citrus pulp and grape marc as barley replacements in calf fattening diets. Animal Production, 23, 129-132. http://dx.doi.org/10.1017/S0003356100031184

Hersom, M. J., Boss, D. L., Wagner, J. J., Zinn, R. A., \& Branine, M. E. (2010). Alpharma Beef Cattle Nutrition Symposium: Alternative energy sources for beef cattle finishing diets. Journal of Animal Science, 88(13), E121-E122. http://dx.doi.org/10.2527/jas.2009-2840

Koopmans, S. J., Guzik, A. C., Van Der Meulen, J., Dekker, R., Kogut, J., Kerr, B. J., \& Southern, L. L. (2006). Effects of supplemental $L$-tryptophan on serotonin, cortisol, intestinal integrity, and behavior in weanling piglets. Journal of Animal Science, 84(4), 963-971.

Lesmeister, K. E., Heinrichs, A. J., \& Gabler, M. T. (2004). Effects of supplemental yeast (Saccharomyces cerevisiae) culture on rumen development, growth characteristics, and blood parameters in neonatal dairy calves. Journal of Dairy Science, 87(6), 1832-39. http://dx.doi.org/10.3168/jds.S0022-0302(04)73340-8

Li, Y. Z., Kerr, B. J., Kidd, M. T., \& Gonyou, H. W. (2006). Use of Supplementary Tryptophan to Modify the Behavior of Pigs. Journal of Animal Science, 84(1), 212-20.

Luciano, G., Monahan, F. J., Vasta, V., Biondi, L., Lanza, M., \& Priolo, A. (2009). Dietary tannins improve lamb meat colour stability. Meat science, $81(1), 120-125$. http://dx.doi.org/10.1016/j.meatsci.2008.07.006

Mader, T. L., \& Davis, M. S. (2004). Effect of management strategies on reducing heat stress of feedlot cattle: feed and water intake. Journal of Animal Science, 82(10), 3077-87.

Min, B. R., Pinchak, W. E., Anderson, R. C., Fulford, J. D., \& Puchala, R. (2006). Effects of condensed tannins supplementation level on weight gain and in vitro and in vivo bloat precursors in steers grazing winter wheat. Journal of Animal Science, 84(9), 2546-2554. http://dx.doi.org/10.2527/jas.2005-590

Mir, Z., \& Mir, P. S. (1994). Effect of the addition of live yeast (Saccharomyces cerevisiae) on growth and carcass quality of steers fed high-forage or high-grain diets and on feed digestibility and in situ degradability. Journal of Animal Science, 72(3), 537-545.

Molina-Alcaide, E., Moumen, A., \& Martín-García, A. I. (2008). By-products from viticulture and the wine industry: potential as sources of nutrients for ruminants. Journal of the Science of Food and Agriculture, 88(4), 597-604. http://dx.doi.org/10.1002/jsfa.3123

Muller, R, \& von Keyserlingk, M. A. G. (2006). Consistency of flight speed and its correlation to productivity and to personality in Bos taurus beef cattle. Applied Animal Behaviour Science, 99(3-4), 193-204. http://dx.doi.org/10.1016/j.applanim.2005.05.012 
Nakanishi, Y., Shigemori, K., Yanagita, K., Mieno, M., \& Manda, M. (1998). Behavioural and growth effect of oral administration of rumen protected tryptophan on weanling beef calves. Memoirs of the Faculty of Agriculture-Kagoshima University (Japan).

Napolitano, F., Girolami, A., \& Braghieri, A. (2010). Consumer liking and willingness to pay for high welfare animal-based products. Trends in Food Science \& Technology, 21(11), 537-543. http://dx.doi.org/10.1016/j.tifs.2010.07.012

Nelson, R. J. (1995). Biological rythms and behaviour. In an introduction to behavioral endocrinology, Sunderland, M.A.: Sinauer Associates, Inc.

Nerantzis, E. T., \& Tartaridis, P. (2006). Integrated Enology-Utilization of winery wastes for the production of high added value products. E-Journal of Science and Technology, 1(3), 79-89.

Nielsen, B., \& Hansen, H. (2004). Effect of grape pomace rich in flavonoids and antioxidants on production parameters in dairy production. Journal of Animal and Feed Sciences, 13(1), 535-538.

Parker, A. J., G. P. Dobson, \& Fitzpatrick, L. A. (2007). Physiological and metabolic effects of prophylactic treatment with the osmolytes glycerol and betaine on Bos indicus steers during long duration transportation. Journal of Animal Science, 85(11), 2916-23. http://dx.doi.org/10.2527/jas.2006-193

Peeters, E., Driessen, B., Steegmans, R., Henot, D., \& Geers, R. (2004). Effect of supplemental tryptophan, vitamin E, and a herbal product on responses by pigs to vibration. Journal of animal science, 82(8), 2410-2420.

Petherick, J. C., Doogan, V. J., Holroyd, R. G., Olsson, P., \& Venus, B. K. (2009). Quality of handling and holding yard environment, and beef cattle temperament: 1. Relationships with flight speed and fear of humans. Applied Animal Behaviour Science, 120(1-2), 18-27. http://dx.doi.org/10.1016/j.applanim.2009.05.009

S.A.S. Institute Inc. (2012). Sample 30584: Analyzing Repeated Measures in JMP Software. JMP.com. Retrieved on November 26, 2012, from http://www.jmp.com/support/notes/30/584.html

Scerra, V., Caparra, P., Foti, F., Lanza, M., \& Priolo, A. (2001). Citrus pulp and wheat straw silage as an ingredient in lamb diets: effects on growth and carcass and meat quality. Small Ruminant Research, 40(1), 51-56. http://dx.doi.org/10.1016/S0921-4488(00)00208-X

Schaefer, A. L., Jones, S. D., \& Stanley, R. W. (1997). The Use of Electrolyte Solutions for Reducing Transport Stress. Journal of animal science, 75(1), 258-65.

Schwartzkopf-Genswein, K. S., Shah, M. A., Church, J. S., Haley, D. B., Janzen, K., Truong, G., ... \& Crowe, T. G. (2012). A comparison of commonly used and novel electronic techniques for evaluating cattle temperament. Canadian Journal of Animal Science, 92(1), 21-31. http://dx.doi.org/10.4141/cjas2011-040

Spanghero, M., Salem, A. Z. M., \& Robinson, P. H. (2009). Chemical composition, including secondary metabolites, and rumen fermentability of seeds and pulp of Californian (USA) and Italian grape pomaces. Animal Feed Science and Technology, 152(3-4), 243-255. http://dx.doi.org/10.1016/j.anifeedsci.2009.04.015

Stockman, C. A., McGilchrist, P., Collins, T., Barnes, A. L., Miller, D., Wickham, S. L., ... \& Fleming, P. A. (2012). Qualitative behavioural assessment of Angus steers during pre-slaughter handling and relationship with temperament and physiological responses. Applied Animal Behaviour Science, 142(3-4), 125-133. http://dx.doi.org/10.1016/j.applanim.2012.10.016

Tsiplakou, E., \& Zervas, G. (2008). The effect of dietary inclusion of olive tree leaves and grape marc on the content of conjugated linoleic acid and vaccenic acid in the milk of dairy sheep and goats. Journal of Dairy Research, 75(03), 270-278. http://dx.doi.org/10.1017/S0022029908003270

Vasta, V., Yáñez-Ruiz, D. R., Mele, M., Serra, A., Luciano, G., Lanza, M., ... \& Priolo, A. (2010). Bacterial and protozoal communities and fatty acid profile in the rumen of sheep fed a diet containing added tannins. Applied and Environmental Microbiology, 76(8), 2549-2555. http://dx.doi.org/10.1128/AEM.02583-09

Voisinet, B. D., Grandin, T., O’Connor, S. F., Tatum, J. D., \& Deesing, M. J. (1997). Bos indicus-cross feedlot cattle with excitable temperaments have tougher meat and a higher incidence of borderline dark cutters. Meat Science, 46(4), 367-377. http://dx.doi.org/10.1016/S0309-1740(97)00031-4

\section{Copyrights}

Copyright for this article is retained by the author(s), with first publication rights granted to the journal.

This is an open-access article distributed under the terms and conditions of the Creative Commons Attribution license (http://creativecommons.org/licenses/by/3.0/). 